\title{
EVALUASI KINERJA OPERASIONAL TERMINAL DARA KOTA BIMA
}

\author{
I WAYAN SUTEJA ${ }^{1)}$, ROHANI ${ }^{2)}$, HASYIM ${ }^{3)}$ \\ Jurusan Teknik Sipil Fakultas Teknik Universitas Mataram
}

e-mail :w.suteja@gmail.com

\section{ABSTRAK}

Terminal Dara merupakan pusat kegiatan masyarakat dalam pemenuhan kebutuhan akan pergerakan dari satu tempat ke tempat lain dengan berbagai tujuan yang digunakan oleh masayarakat Kota dan Kabupaten Bima. Terminal Dara mengalami penurunan dan peningkatan jumlah angkutan dari tahun ke tahun, kondisi ini membuat fasilitasdan kinerja operasional di Terminal Dara sangat penting. Tujuan penelitian ini untuk mengetahui kinerja operasional dan fasilitas serta luasan fasilitas Terminal Dara saat ini.

Metode yang digunakan untuk penelitian ini adalah survey langsung di lapangan untuk data primer dengan cara mencatat plat nomor dan waktu masuk dan keluar bus dan kendaraan pengunjung di pintu masuk dan pintu keluar serta mencatat jumlah penumpang dan pengguna ruang tunggu, jumlah seat pada ruang tunggu penumpang, kapasitas bus dan fasilitas dan luasan fasilitas terminal. Pengambilan data dilakukan selama tiga hari dengan durasi waktu 13 jam disetiap harinya.

Berdasarkan hasil analisis kinerja yang telah dilakukan, diperoleh nilai untuk analisis antrian bus $\rho=$ $2,11>1$ yang menandakan terjadi antrian pelayanan bus di Terminal Dara. Nilai waktu antara rata - rata kedatangan tertinggi sebesar 17 menit 22 detik dan waktu antara rata - rata keberangkatan tertinggi sebesar 12 menit 23 detik. Load factor keberangkatan tertinggi sebesar 81,44\% pada ANGDES dan load factor kedatangan tertinggi sebesar 73,64\% pada ANGDES juga. Kebutuhan ruang parkir untuk kendaraan pribadi mobil dan sepeda motor sebesar $128 \mathrm{~m}^{2}$ masih bisa dilayani oleh areal parkir kendaraan pribadi terminal, sedangkan areal parkir untuk bus sudah tidak mampu melayani bus yang parkir di areal parkir bus dengan nilai kebutuhan ruang parkir 902,5 $\mathrm{m}^{2}$ sedangkan luas areal parkir bus saat ini sebesar $631,25 \mathrm{~m}^{2}$. Berdasarkan hasil survey yang ada, Terminal Dara perlu merenovasi jalur keberangkatan bus dan ruang tunggu penumpang, atau bisa merelokasi terminal ke lahan yang lebih luas.

Kata kunci: Terminal Dara, kinerja operasional terminal, fasilitas terminal.

\section{ABSTRACT}

Terminal Dara is the center of community activities in meeting the needs for movement from one place to another with various purposes used by the people of the of Bima City and Regency. Terminal Dara has experienced a decline and an increase in the number of transportation from year to year; this condition makes facilities and operational performance at the Dara Terminal become very important. The purpose of this study is to determine the operational performance and facilities as well as the current area of Dara Terminal facilities.

The method used in this study is a direct survey in the field for primary data by recording the bus license plate, time of entry and exit of buses and visitors vehicles at the entrance and exit gate and recording the number of passengers and users of waiting rooms, the number of seats in passenger waiting rooms, and bus station facilities. Data collection is carried out for three days with duration of 13 hours each day.

Based on the results of the analysis of the performance that has been carried out, the value for the bus queue analysis $\rho=2.11>1$ indicates that there is a queue of bus services at Dara bus station. The highest value of arrival average time headway is 17 minutes 22 seconds and the departures average time headway is 12 minutes 23 seconds. The highest departure load factor is $81.44 \%$ in the ANGDES and the highest load factor is 73.64\% in ANGDES too. The parking space requirement for cars and motorbikes of $128 \mathrm{~m}^{2}$ can still be served by vehicle parking area in bus station, while the parking area for bus is not able to serve bus which parked in the bus parking area with the value of parking space needs $902.5 \mathrm{~m}^{2}$ while the area the current bus parking area is $631.25 \mathrm{~m}^{2}$. Based on the results of the performance analysis that has been done, the value obtained for bus queue analysis $\rho=2.11>1$ indicates that there is a queue of bus services in Dara Terminal. The time between the highest average arrivals is 17 minutes 22 seconds and the time between the highest average departures is 12 minutes 23 seconds. The highest departure load factor was $81.44 \%$ at 
ANGDES and the highest arrival load factor was 73.64\% at ANGDES as well. The need for parking spaces for private cars and motorbikes of $128 \mathrm{~m}^{2}$ can still be served by the terminal private vehicle parking area, while the parking area for buses is not able to serve buses that park in the bus parking area with a value of $902.5 \mathrm{~m}^{2}$ of parking space while the area the bus parking area is currently $631.25 \mathrm{~m}^{2}$. Based on existing survey results, the bus departure lane and passenger lounge of Terminal Daral need to be renovated, or they can relocate the terminal to a wider area.

Keywords: Dara bus station, Bus Station Operational Performance, Bus station Facilities.

\section{PENDAHULUAN}

\section{Latar Belakang}

Transportasi dalam pembangunan nasional memiliki peranan yang penting dan strategis, khususnya di daerah Bima. Transportasi yang lancar mempermudah pertumbuhan perekonomian.Terlaksananya keterpaduan intra dan antar moda secara lancar dan tertib di daerah Bima, perlu menyelenggarakan suatu terminal.

Terminal pada hakekatnya merupakan simpul dari sistem jaringan angkutan jalan yang fungsi utamanya sebagai tempat pelayanan umum untuk naik turun penumpang dan atau bongkar muat barang, tempat pengendalian lalu lintas dan angkutan kendaraan umum, serta sebagai tempat perpindahan intra dan antar moda angkutan.

Terminal Dara tidak hanya melayani masyarakat Kota Bima saja, masyarakat Kabupaten Bima pun juga turut menggunakan terminal ini.Terminal Dara mengalami penurunan dan peningkatan angkutan dilihat dari tahun ke tahun, menurut data dari Badan Pusat Statistik Kota Bima jumlah angkutan umum untuk tahun 2013 sebanyak 283 angkutan baik itu AKAP, AKDP maupun AK dan ANGDES, untuk tahun 2014 dan 2015 sendiri jumlah angkutan umum sebanyak 624 angkutan dan mengalami penurunan jumlah angkutan pada tahun 2016 dengan jumlah angkutan sebanyak 268 angkutan, kemudian mengalami peningkatan kembali pada tahun 2017 dengan jumlah angkutan sebanyak 330.

Sebagai satu-satunya terminal bus di Bima yang termasuk dalam klasifikasi terminal penumpang tipe A yang melayani angkutan Antar Kota Antar Provinsi (AKAP), angkutan Antar Kota Dalam Provinsi (AKDP) dan Angkutan Desa (ANGDES) maka kinerja operasional terminal Dara sangatlah penting karena pelayanan terminal akan berpengaruh pada kelancaran jaringan pelayanan bus.

Terminal Dara memiliki peran yang penting bagi masyarakat, khususnya masyarakat Kota dan Kabupaten Bima, maka atas dasar tersebut penelitian guna mengevaluasi kinerja terminal perlu dilakukan. Oleh karena itu, penelitian ini mengambil judul "Evaluasi Kinerja Operasional Terminal Dara Kota Bima".

\section{Tujuan Penelitian}

Adapun tujuan dari penelitian ini adalah sebagai berikut:

1. Mengetahui kinerja Terminal Dara saat ini sesuai dengan indikator kinerja terminal yang ada.

2. Mengetahui kondisi fasilitas dan luasan fasilitas yang ada di Terminal Dara.

3. Memberikan solusi untuk peningkatan kinerja operasional Terminal Dara.

\section{METODE PENELITIAN}

\section{Pengumpulan Data}

Pengumpulan data merupakan suatu tahap dalam memproses data-data yang akan digunakan dalam analisis penelitian. Data-data tersebut berupa data primer dan data sekunder.

a) Data Primer yang diperlukan: Data jumlah kedatangan dan keberangkatan bus, Data waktu bus masuk dan keluar terminal, Data waktu pelayanan bus, Data jumlah penumpang, Data jumlah kendaraan pengunjung dan penumpang yang parkir di areal terminal, Data kapasitas tempat duduk (seat) pada bus dan jumlah pengguna dan kapasitas tempat duduk pada ruang tunggu terminal.

b). Data Sekunder meliputi : Data jumlah kedatangan dan keberangkatan bus,Data waktu bus masuk dan keluar terminal, Data jumlah penumpang, Layout Terminal Dara, Kota Bima. 


\section{Pelaksanaan Penelitian}

Adapun langkah-langkah penelitian di lapangan dilakukan melalui tahap-tahap sebagai berikut :

1. Penetapan waktu dan lokasi pengambilan data. Pengambilan data dilakukan selama 3 (tiga) hari yaitu pada hari senin, sabtu dan minggu. Lokasi pengambilan data dilakukan di areal Terminal Dara Kota Bima yang berada pada jalan Sultan Muhammad Salahuddin, Kota Bima.

2. Pelaksanaan survey

a) Survey volume parker.Pencatatan data survey ini dilakukan dengan menempatkan satu orang surveyor pada pintu masuk terminal, dan satu surveyor lagi pada pintu keluar terminal, kedua surveyor ini mencatat nomor identitas dan waktu kendaraan yang masuk dan keluar.

b) Survey luasan fasilitas di terminal.Survey ini dilakukan untuk mengetahui luasan-luasan fasilitas di terminal, fasilitas yang dilakukan pengukuran luasannya sesuai pada Kebutuhan Luasan

c) Survey jumlah penumpang dan volume bus.Survey ini dimaksudkan untuk mengetahui jumlah penumpang yang menggunakan jasa terminal. Survey dilakukan dengan menempatkan surveyor ditempat bus menurunkan penumpang dan ditempat parkir bus. Surveyor mencatat nomor identitas bus, nama armada bus, jumlah penumpang yang naik dan turun dari bus dan mencatat waktu kedatangan dan keberangkatan bus.

d) Survey kapasitas tempat duduk pada bus. Survey ini dimaksudkan untuk mengetahui kapastitas tempat duduk penumpang dalam bus, sehingga bisa dicari nilai okupansi.

e) Survey waktu pelayanan.Survey ini dilakukan untuk mengetahui durasi dari waktu pelayanan terminal terhadap bus yang datang.

f) Survey jumlah pengguna pada ruang tunggu. Survey ini dilakukan untuk mengetahui banyaknya pengguna ruang tunggu terminal Dara dalam satuan waktu (digunakan per jam).

\section{HASIL DAN PEMBAHASAN}

\section{Layout Terminal}

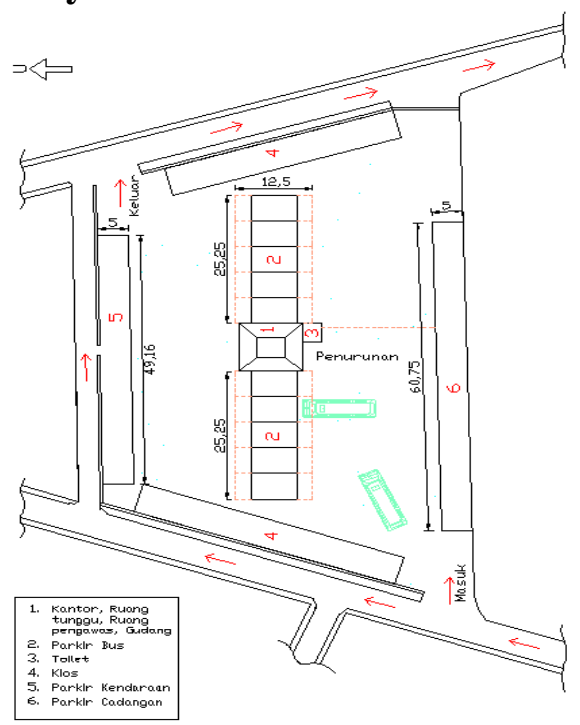

\section{Data Volume Bus dan Penumpang}

Tabel 1. Jumlah Bus Keluar Terminal

\begin{tabular}{|c|c|c|c|c|c|}
\hline \multirow{2}{*}{ HariTanggal } & \multicolumn{4}{|c|}{ Keluar } & \multirow{2}{*}{$\begin{array}{c}\text { Jumlah } \\
\text { Penumpang } \\
\text { Naik } \\
\end{array}$} \\
\hline & AKAP & AKDP & ANGDES & Jumlah & \\
\hline Sabtu, 27 Oktober 2019 & 4 & 30 & 20 & 54 & 754 \\
\hline Minggu, 28 Oktober 2019 & 4 & 30 & 22 & 56 & 905 \\
\hline Senin, 29 Oktober 2019 & 4 & 30 & 24 & 58 & 758 \\
\hline
\end{tabular}

Sumber : Hasil Analisis

Gambar 1. Layout Terminal Dara

\section{Data Volume Parkir}

Tabel 2. Data Volume Parkir Kendaraan

\begin{tabular}{|c|c|c|c|c|}
\hline \multirow{2}{*}{ Hari/Tanggal } & \multicolumn{3}{|c|}{ Jenis Kendaraan } & \multirow{2}{*}{ Total } \\
\cline { 2 - 4 } & Bus & Mobil & Sepeda motor & \\
\hline Sabtu, 27 Oktober 2018 & 72 & 10 & 182 & 272 \\
\hline Minggu, 28 Oktober 2018 & 65 & 19 & 167 & 260 \\
\hline Senin, 29 Oktober 2018 & 71 & 22 & 188 & 287 \\
\hline
\end{tabular}




\section{Data Luas Parkir}

Terminal Dara memiliki 10 ruang parkir untuk bus, 5 ruang parkir disebelah barat ruang perkantoran dan 5 lagi disebelah timur ruang perkantoran, lebar total ruang parkir bus adalah sebesar 50,5 $\mathrm{m}$ dan panjangnya sebesar 12,5 m. Berikut adalah perhitungan untuk luasan parkir bus di terminal Dara :

Luas areal parkir bus $\quad=50,5 \mathrm{~m} \times 12,5 \mathrm{~m}=631,25 \mathrm{~m}^{2}$

Terminal Dara memiliki dua areal parkir kendaraan pribadi, parkir utama yang berada disebelah utara dan areal parkir cadangan berada disebelah selatan

Berikut perhitungan luasan areal parkir kendaraan dan areal parkir cadangan :

Luas areal parkir kendaraan

$$
=49,16 \mathrm{~m} \times 5 \mathrm{~m}=245,776 \mathrm{~m}^{2}
$$

Luas areal parkir cadangan

$$
=60,75 \mathrm{~m} \times 5 \mathrm{~m}=303,75 \mathrm{~m}^{2}
$$

\section{Antrian Bus}

Model antrian multi chanel-single phase dimana Terminal Dara memiliki satu jalur kedatangan dan memiliki 10 jalur keberangkatan

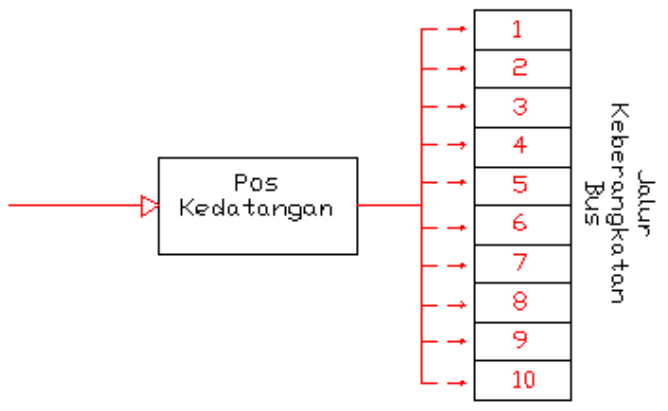

Gambar 2. Sistem Antrian Bus Terminal Dara

Analisis ini dilakukan pada jam sibuk terminal. Tingkat kedatangan bus per jam dapat dilihat pada grafik.

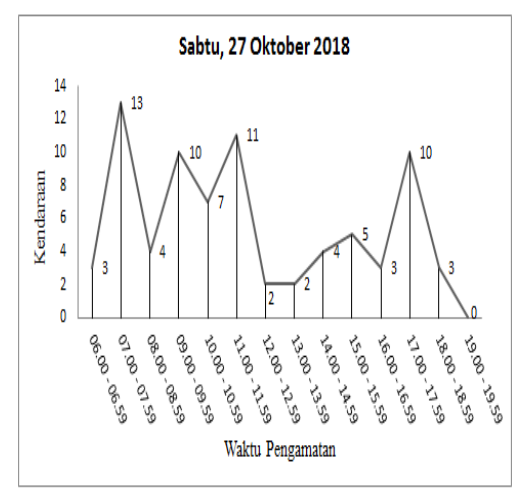

Gambar 3. Grafik Kedatangan Bus Hari Sabtu

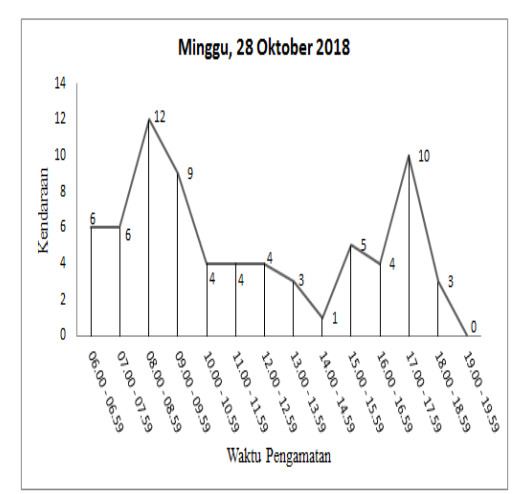

Gambar 4. Grafik Kedatangan Bus Hari Minggu

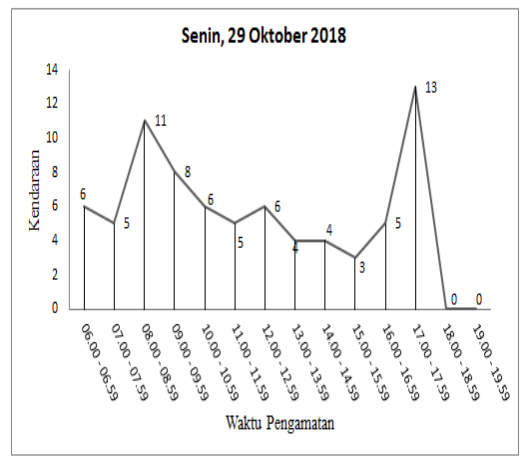

Gambar 5. Grafik Kedatangan Bus Hari Senin

Dari grafik dapat dilihat bahwa jumlah kedatangan bus tertinggi terjadi pada hari Sabtu pada jam 07.00 sampai 07.59 dan hari Senin jam 17.00 sampai 17.59, yaitu sebanyak 13 kendaraan. 
Tabel 3. Data Waktu Pelayanan Hari Sabtu

\begin{tabular}{|c|c|c|c|}
\hline No. Plat & Waktu Datang & Waktu Keluar & Waktu Pelayanan \\
\hline EA 7738 YZ & 07.13 & 08.00 & 47 menit \\
\hline EA 7320 X & 07.19 & 08.15 & 56 menit \\
\hline EA 7751 SZ & 07.01 & 08.35 & 94 menit \\
\hline EA 7350 S & 07.12 & 09.00 & 81 menit \\
\hline EA 7336 XA & 07.39 & 09.00 & 104 menit \\
\hline EA 7326 X & 07.31 & 09.15 & 106 menit \\
\hline EA 7266 X & 07.29 & 09.15 & 149 menit \\
\hline EA 7251 XZ & 07.01 & 09.30 & 157 menit \\
\hline EA 7258 XZ & 07.18 & 10.00 & 160 menit \\
\hline EA 7764 SA & 07.23 & 10.00 & 19 menit \\
\hline EA 7346 X & 07.55 & 11.35 & 24 menit \\
\hline EA 7345 X & 07.20 & 07.39 & 97.5 menit \\
\hline EA 7305 X & 07.59 & 08.23 & \\
\hline
\end{tabular}

Tingkat kedatangan $(\lambda)=13$ kendaraan/jam

$\mathrm{WP}=97,5$ menit $/$ kendaraan

$=1,62 \mathrm{jam} /$ kendaraan

Tingkat pelayanan $(\mu)=1 / \mathrm{WP}$

$$
\begin{aligned}
& =1 / 1,62 \\
& =0,615 \mathrm{kendaraan} / \mathrm{jam}
\end{aligned}
$$

Jumlah jalur keberangkatan $=10$ jalur

Berikut adalah perhitungan berdasarkan model antrian multi chanel-single phase untuk menentukan efektifitas dari model antrian (Prasetya, 2018).

Tingkat kegunaan fasilitas pelayanan

$\rho=\frac{\lambda}{s \mu}=\frac{13}{10 x 0,615}=2,11>1$

Probabilitas tidak ada bus dalam sistem

$\mathrm{P}_{\mathrm{o}}=\frac{1}{\sum_{n=0}^{s=1}\left[\frac{(\lambda / \mu)^{n} n}{n !}\right]+1-\frac{\left(\frac{\lambda}{\mu}\right)^{2}}{s !\left(1-\frac{\lambda}{s \mu}\right)}}=$

1

$\sum_{n=0}^{g=1}\left[\frac{(13 / 0,615)^{\wedge} 0}{0 !}\right]+\left[\frac{(13 / 0,615)^{n} 1}{1 !}\right]+1-\frac{\left(\frac{13}{0,615}\right)^{2}}{10 !\left(1-\frac{13}{10 \times 0,615}\right)}$

$=0,0452$

Rata-rata jumlah bus pada sistem

$L s=\frac{\lambda \mu\left(\frac{\lambda}{\mu}\right)^{n 2}}{(s-1)^{r}(s \mu-\lambda)^{2}} p_{o}+\frac{\lambda}{s \mu}$ 
$=\frac{13 \times 0,615\left(\frac{18}{0,615}\right)^{2}}{(10-1) \times(10 x 0,615-13)^{2}} \times 0,0452+\frac{13}{0,615}$

$=21,14$

Rata-rata waktu yang dihabiskan dalam sistem

$W s=\frac{L s}{\lambda}=\frac{21,14}{13}=1,626 \mathrm{jam}$

Rata-rata waktu yang dihabiskan dalam antrian

$W q=W s \frac{1}{\mu}=1,626 \times \frac{1}{0,615}=2,644 \mathrm{jam}$

\section{Waktu Antara (Time Headway)}

Time headway kedatangan dan keberangkatan bus tertinggi terjadi pada hari Minggudengan rata-rata time headway kedatangansebesar 17,37 menit atau 17 menit 22 detik dan rata-rata time headway keberangkatan sebesar 12,38 menit atau 12 menit 23 detik.

Tabel 4. Waktu Antara Kedatangan Bus

\begin{tabular}{|c|c|}
\hline Hari/Tanggal & Waktu Antara rata-rata (menit) \\
\hline Sabtu, 27 Oktober 2018 & 9,65 \\
\hline Minggu, 28 Oktober 2018 & 17,37 \\
\hline Senin, 29 Oktober 2018 & 14,60 \\
\hline
\end{tabular}

Tabel 5. Waktu Antara Keberangkatan Bus

\begin{tabular}{|c|c|}
\hline Hari/Tanggal & Waktu Antara rata-rata (menit) \\
\hline Sabtu, 27 Oktober 2018 & 11,99 \\
\hline Minggu, 28 Oktober 2018 & 12,38 \\
\hline Senin, 29 Oktober 2018 & 12,27 \\
\hline
\end{tabular}

\section{Tingkat Okupansi Penumpang}

Load factor rata-rata keberangkatan penumpang tertinggi untuk AKAP sebesar 55\%, untuk AKDP sebesar 52,88\% dan untuk ANGDES sebesar $81,44 \%$. Sedangkan load factor rata-rata kedatangan penumpang tertinggi tertinggi untuk AKAP sebesar 64,28\%, untuk AKDP sebesar 59\% dan untuk ANGDES sebesar 73,64\%.

Dari hasil perhitungan load factor ANGDES melebihi nilai 70\% yaitu standar efektif untuk load factor berdasarkan ketentuan Dinas Perhubungan (2002), namun tidak melebihi nilai 100\%.

Tabel 6.Load Factor Rata-rata Keberangkatan Penumpang

\begin{tabular}{|c|c|c|c|}
\hline Hari/Tanggal & AKAP & AKDP & ANGDES \\
\hline Sabtu, 27 Oktober 2018 & $36,96 \%$ & $52,88 \%$ & $59,06 \%$ \\
\hline Minggu, 28 Oktober 2018 & $55 \%$ & $52,87 \%$ & $81,44 \%$ \\
\hline Senin, 29 Oktober 2018 & $29,46 \%$ & $49,10 \%$ & $61,46 \%$ \\
\hline
\end{tabular}

Tabel 7.Load Factor Rata-rata Kedatangan Penumpang

\begin{tabular}{|c|c|c|c|}
\hline Hari/Tanggal & AKAP & AKDP & ANGDES \\
\hline Sabtu, 27 Oktober 2018 & $60 \%$ & $56,35 \%$ & $61,96 \%$ \\
\hline Minggu, 28 Oktober 2018 & $64,28 \%$ & $58,71 \%$ & $72,55 \%$ \\
\hline Senin, 29 Oktober 2018 & $48,57 \%$ & $59 \%$ & $73,64 \%$ \\
\hline
\end{tabular}




\section{Kebutuhan Ruang Parkir}

Akumulasi maksimal parkir sepeda motor sebesar 27 kendaraan yang terjadi pada hari Minggu pukul 09.15-09.30 dan pukul 09.3009.45



Gambar 6. Grafik Akumulasi Parkir Sepeda Motor Hari Minggu
Akumulasi maksimal parkir mobil sebesar 7 kendaraan yang terjadi pada hari Senin pukul $18.30-18.45$

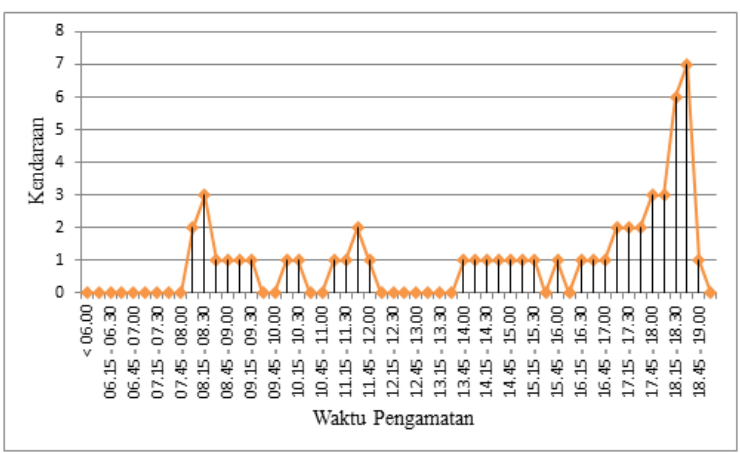

Gambar 7. Grafik Akumulasi Parkir Mobil Senin

Total kebutuhan ruang parkir untuk sepeda motor dan mobil sebesar $128 \mathrm{~m}^{2}$, jumlah tersebut lebih kecil jika dibandingkan luas areal parkir yang tersedia yaitu sebesar $245,776 \mathrm{~m}^{2}$.

\section{Tabel 8. Kebutuhan Ruang Parkir Sepeda Motor}

\begin{tabular}{|c|c|c|c|}
\hline Waktu Pengamatan & \multirow{2}{*}{ SRP $\left(\mathrm{m}^{2}\right)$} & \multicolumn{2}{|c|}{ Areal Parkir } \\
\cline { 3 - 4 } & & JK (kend) & KRP $\left(\mathrm{m}^{2}\right)$ \\
\hline Sabtu, 27 Oktober 2018 & 1.5 & 15 & 22.5 \\
\hline Minggu, 28 Oktober 2018 & 1.5 & 27 & 40.5 \\
\hline Senin, 29 Oktober 2018 & 1.5 & 21 & 31.5 \\
\hline
\end{tabular}

Tabel 9. Kebutuhan Ruang Parkir Mobil

\begin{tabular}{|c|c|c|c|}
\hline Waktu Pengamatan & \multirow{2}{*}{ SRP $\left(\mathrm{m}^{2}\right)$} & \multicolumn{2}{|c|}{ Areal Parkir } \\
\cline { 3 - 4 } & & JK (kend) & KRP $\left(\mathrm{m}^{2}\right)$ \\
\hline Sabtu, 27 Oktober 2018 & 12,5 & 2 & 25 \\
\hline Minggu, 28 Oktober 2018 & 12,5 & 6 & 75 \\
\hline Senin, 29 Oktober 2018 & 12,5 & 7 & 87,5 \\
\hline
\end{tabular}

Akumulasi maksimal parkir bus sebesar 19 kendaraan yang terjadi pada hari Senin pukul 10.15-10.30 yang melebihi dari jumlah ruang parkir bus yang tersedia pada terminal Dara yaitu sebanyak 10 ruang parkir.

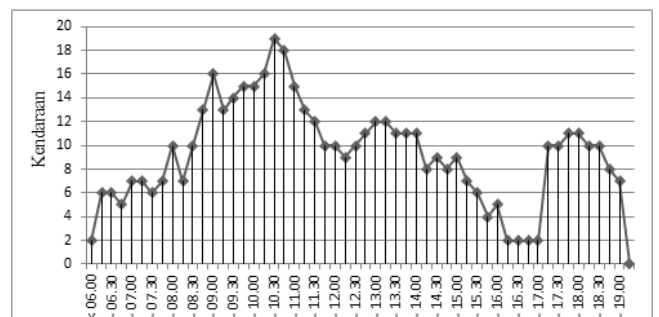

Gambar 8. Grafik Akumulasi Parkir Bus Hari Senin 
Hasil perhitungan kebutuhan ruang parkir untuk bus dapat dilihat pada tabel berikut.

Tabel 10. Kebutuhan Ruang Parkir Bus

\begin{tabular}{|c|c|c|c|}
\hline \multirow{2}{*}{ Waktu Pengamatan } & \multirow{2}{*}{ SRP $\left(\mathrm{m}^{2}\right)$} & \multicolumn{2}{|c|}{ Areal Parkir } \\
\cline { 3 - 4 } & & JK (kend) & KRP $\left(\mathrm{m}^{2}\right)$ \\
\hline Sabtu, 27 Oktober 2018 & 47.5 & 14 & 665 \\
\hline Minggu, 28 Oktober 2018 & 47.5 & 18 & 855 \\
\hline Senin, 29 Oktober 2018 & 47.5 & 19 & 902.5 \\
\hline
\end{tabular}

\section{Rasio Ruang Tunggu}

Rasio ruang tunggu penumpang pada tiga hari waktu penelitian melebihi nilai $100 \%$, hal ini menjelaskan bahwa kapasitas ruang tunggu penumpang terminal Dara saat ini tidak mampu melayani pengguna ruang tunggu penumpang.

Tabel 11. Hasil Rasio Ruang Tunggu

\begin{tabular}{|c|c|c|c|}
\hline Hari/Tanggal & $\begin{array}{c}\text { Total Pengguna Ruang } \\
\text { Tunggu }\end{array}$ & Kap. Kursi & $\begin{array}{c}\text { Rasio Ruang Tunggu } \\
(\%)\end{array}$ \\
\hline Sabtu & 39 & 32 & 122 \\
\hline Minggu & 42 & 32 & 131 \\
\hline Senin & 43 & 32 & 134 \\
\hline
\end{tabular}

\section{Fasilitas dan Luasan Fasilitas}

Dari hasil pengamatan dilapangan diketahui bahwa ada beberapa fasilitas di Terminal Dara yang tidak tersedia berdasarkan tabel kebutuhan luasan terminal. Fasilitas dan luasan fasilitas yang tidak sesuai standar dari tabel kebutuhan luasan terminal menandakan bahwa Terminal Dara adalah terminal Tipe A kelas III berdasarkan peraturan Direktorat Jenderal Perhubungan Darat (2017).

Tabel 12. Fasilitas dan Luasan Fasilitas Terminal Dara

\begin{tabular}{|c|c|c|c|c|}
\hline \multicolumn{2}{|l|}{ A. Kendaraan } & Satuan & Standarisasi & Lapangan \\
\hline \multirow[t]{5}{*}{ Ruang Parkir } & AKAP & $\mathrm{m}^{2}$ & 1,120 & \multirow{4}{*}{631,25} \\
\hline & AKDP & $\mathrm{m}^{2}$ & 540 & \\
\hline & $\mathrm{AK}$ & $\mathrm{m}^{2}$ & 800 & \\
\hline & ADES & $\mathrm{m}^{2}$ & 900 & \\
\hline & Kend. Pribadi & $\mathrm{m}^{2}$ & 600 & 245,8 \\
\hline \multicolumn{2}{|l|}{ Ruang Service } & $\mathrm{m}^{2}$ & 500 & Tidak Ada \\
\hline \multicolumn{2}{|l|}{ Pompa bensin } & $\mathrm{m}^{2}$ & 500 & Tidak Ada \\
\hline \multicolumn{2}{|c|}{ Sirkulasi Kendaraan } & $\mathrm{m}^{2}$ & 3,960 & 2003,2 \\
\hline \multicolumn{2}{|c|}{ Bengkel } & $\mathrm{m}^{2}$ & 150 & Tidak Ada \\
\hline \multicolumn{2}{|l|}{ Ruang Istrihat } & $\mathrm{m}^{2}$ & 50 & Tidak Ada \\
\hline \multicolumn{2}{|l|}{ Gudang } & $\mathrm{m}^{2}$ & 25 & 3,3 \\
\hline \multicolumn{2}{|c|}{ Pelataran Parkir Cadangan } & $\mathrm{m}^{2}$ & 1,980 & 303,7 \\
\hline \multicolumn{5}{|c|}{ B. Pemakai Jasa } \\
\hline \multicolumn{2}{|l|}{ Ruang Tunggu } & $\mathrm{m}^{2}$ & 2,625 & 75,1 \\
\hline \multicolumn{2}{|c|}{ Sirkulasi Manusia } & $m^{2}$ & 1,050 & 75,1 \\
\hline \multicolumn{2}{|c|}{ Kamar Mandi } & $\mathrm{m}^{2}$ & 72 & 11,7 \\
\hline \multicolumn{2}{|l|}{ Kios } & $\mathrm{m}^{2}$ & 1,575 & 457,8 \\
\hline \multicolumn{2}{|l|}{ Mushola } & $\mathrm{m}^{2}$ & 72 & Tidak Ada \\
\hline \multicolumn{5}{|l|}{ C. Operasional } \\
\hline \multicolumn{2}{|c|}{ Ruang Administrasi } & $\mathrm{m}^{2}$ & 78 & \multirow{2}{*}{97,9} \\
\hline \multicolumn{2}{|c|}{ Ruang Perkantoran } & $\mathrm{m}^{2}$ & 150 & \\
\hline \multicolumn{2}{|l|}{ Loket } & $\mathrm{m}^{2}$ & 3 & Tidak Ada \\
\hline \multicolumn{2}{|l|}{ Peron } & $\mathrm{m}^{2}$ & 4 & Tidak Ada \\
\hline \multicolumn{2}{|l|}{ Retribusi } & $\mathrm{m}^{2}$ & 6 & Tidak Ada \\
\hline \multicolumn{2}{|c|}{ Ruang Informasi } & $\mathrm{m}^{2}$ & 12 & \multirow{2}{*}{22,8} \\
\hline \multicolumn{2}{|c|}{ Ruang Pengawas } & $\mathrm{m}^{2}$ & 23 & \\
\hline \multicolumn{2}{|c|}{ Ruang Pertolongan Pertama } & $\mathrm{m}^{2}$ & 45 & Tidak Ada \\
\hline \multicolumn{2}{|c|}{ D. Ruang Luar (tidak efektif) } & $\mathrm{m}^{2}$ & 6,653 & 2,857 \\
\hline \multicolumn{2}{|l|}{ Luas Total } & $\mathrm{m}^{2}$ & 23,494 & 6,454 \\
\hline
\end{tabular}




\section{SIMPULAN DAN SARAN}

\section{Simpulan}

1. Kinerja terminal Dara

a) Terjadi antrian pada jalur keberangkatan Terminal Dara diakibatkan oleh nilai tingkat pelayanan 0,615 kendaraan/jam lebih kecil dibanding tingkat kedatangan bus 13 kendaraan/jam.

b) Nilai headway rata-rata kedatangantertinggi sebesar 17 menit 22 detik dan nilai headway rata-rata keberangkatan tertinggi sebesar 12 menit 23 detik. Nilai tersebut lebih besar dari nilai headway ideal menurut Departemen Perhubungan yaitu sebesar 5-10 menit.

c) Load factor rata-rata keberangkatan penumpang tertinggi AKAP sebesar 55\%, AKDP sebesar 52,88\% dan ANGDES sebesar 81,44\%. Sedangkan load factor rata-rata kedatangan penumpang tertinggi tertinggi AKAP sebesar 64,28\%, AKDP sebesar 59\% dan ANGDES sebesar 73,64\%. Dari hasil perhitungan load factor ANGDES melebihi nilai 70\% yaitu standar efektif untuk load factor berdasarkan ketentuan Dinas Perhubungan (2002), namun tidak melebihi nilai $100 \%$.

d) Total kebutuhan ruang parkir kendaraan jenis sepeda motor dan mobil adalah $128 \mathrm{~m}^{2}$ lebih kecil dari luas areal parkir kendaraan yang tersedia yaitu $245,776 \mathrm{~m}^{2}$. Kebutuhan ruang parkir untuk bus sebesar 902,5 $\mathrm{m}^{2}$ sedangkan luas areal parkir bus yang tersedia sebesar $631,25 \mathrm{~m}^{2}$, hal ini menunjukkan areal parkir bus terminal sudah tidak mampu melayani bus yang menggunakan areal parkir bus terminal.

e) Nilai rasio ruang tunggu dalam tiga hari pengamatan adalah $122 \%, 131 \%$ dan $134 \%$, nilai tersebut melebihi nilai $100 \%$ yang menandakan bahwa ruang tunggu penumpang terminal Dara saat ini tidak mampu melayani pengguna ruang tunggu.

2. Beberapa fasilitas di terminal Dara ada yang tidak tersedia seperti, ruang servis, ruang istirahat, loket, peron dan retribusi. Berdasarkan hasil perhitungan luas ruang penumpang dengan hasil perhitungan sebesar $315 \mathrm{~m}^{2}$, luasan ruang tunggu terminal Dara masih kurang dengan luasan sekarang sebesar 75,1 $\mathrm{m}^{2}$.

\section{Saran}

1. Untuk meningkatkan kinerja operasional, Terminal Dara perlu untuk merenovasi areal parkir bus atau jalur keberangkatan karena sudah tidak dapat menampung bus yang parkir maupun bus yang akan menaikan penumpang pada jam sibuk, dan perlu untuk merenovasi ruang tunggu penumpang karena sudah tidak dapat menampung pengguna ruang tunggu.

2. Perlu adanya pemisahan parkir bus atau jalur keberangkatan sesuai dengan jenis bus yang ada di terminal Dara yaitu AKAP, AKDP dan ANGDES, dan perlu adanya pemisah antara parkir mobil dan parkir sepeda motor.

3. Memfungsikan lahan kosong sebelah utara terminal untuk menambah luasan terminal, dijadikan ruang parkir untuk bus dan membangun beberapa fasilitas terminal, seperti : ruang pembelian tiket / loket, ruang servis dan ruang istirahat.

4. Perlu adanya penjadwalan untuk beberapa bus AKDP dan ANGDES yang memiliki trayek di wilayah Kabupaten Bima dan Kabupaten Dompu.

\section{DAFTAR PUSTAKA}

Abubakar, I. dkk. 1996. Menuju Lalu Lintas dan Angkutan Jalan Yang Tertib. Direktorat Jenderal Perhubungan Darat Kementerian Perhubungan RI. Jakarta.

Alit W., A A S, 2016, Kinerja Operasional Pelayanan Terminal Kabupaten Gresik, Universitas PGRI Adi Buana. Surabaya.

Arifin, T S., 2017, Analisis Kinerja Operasional Terminal Samarinda Seberang,Universitas Mulawarman. Samarinda.

Batti, J F., 2002, Analisis Antrian Pada Terminal Karombosan Kota Manado, Universitas Tadulako. Palu.

Frans, J H., 2017, Evaluasi Dan Pengembangan Kapasitas Terminal Bus Kota Kupang,FST UNDANA. Kupang.

Keputusan Direktorat Jenderal Perhubungan Darat, 1996, Nomor 272/HK.105/DRJD/96, Pedoman Teknis Penyelenggaraan Fasilitas Parkir. 
Kristianto, H A, 2008, Evaluasi Kinerja Dan Kapasitas Terminal Bus Harja Mukti Cirebon, Universitas Muhammadiyah. Surakarta.

LPM ITB, 1997, Perencanaan Sistem Angkutan Umum, Bandung.

LPM UGM, 1994, Final Report Untuk Studi Standarisai Perencanaan Kebutuhan Fasilitas Perpindahan Angkutan Umum di Wilayah Perkotaan, Yogyakarta.

Prasetya, I D., 2018, Aplikasi Antrian Multi Channel Single Phase Pada Pelayanan Klinik Gigi Berbasis Web,Universitas Sanata Dharma. Yogyakarta.

Peraturan Menteri Perhubungan Republik Indonesia, 2015, PM/132/2015, Penyelenggaraan Terminal Penumpang Angkutan Jalan.

Sutomy, Lalu, 2010, Evaluasi Efektivitas Areal Parkir Untuk Minibus Di Dalam Terminal Mandalika, Universitas Mataram. Mataram.

Surat Keputusan Direktur Jenderal Perhubungan Darat, 2017, SK/6521/2017, Pedoman Teknis Kriteria Penetapan Kelas Terminal.

Warpani, S., 1990, Merencankan Sistem Perangkutan, Erlangga, Surabaya.

Warpani, S., 2002, Pengelolaaan Lalu Lintas dan Angkutan Jalan, ITB, Bandung.

Zakaria, M., 2010, Studi Karakteristik Parkir dan Kebutuhan Luas Terminal Tegal sebagai Terminal Bus Tipe A,Universitas Sebelas Maret. Surakarta. 